\title{
Commentary The electrocardiogram for sepsis: how close are we?
}

\author{
Mitchell M Levy
}

Rhode Island Hospital/Brown University, 593 Eddy St, Providence, RI 02903, USA

Corresponding author: Mitchell M Levy, Mitchell_Levy@brown.edu

Published: 26 June 2007

This article is online at http://ccforum.com/content/11/3/144

(c) 2007 BioMed Central Ltd

See related research by Kofoed et al., http://ccforum.com/content/11/2/R38
Critical Care 2007, 11:144 (doi:10.1186/cc5943)

and specificity for diagnosing the presence of bacterial infection [6]. In addition, recent data suggest that biomarkers can also aid clinicians in risk assessment [7].

In daily clinical practice the diagnosis of sepsis is imprecise and often delayed. In part, this is because the diagnosis is based on a clinical picture of signs and symptoms. This basis has significant implications, as there is evidence that early events in sepsis may determine outcome. A more objective set of measurements for confirming the diagnosis of sepsis has long been sought. Several sepsis biomarkers have been evaluated and shown to have a moderate degree of sensitivity and specificity for diagnosing the presence of bacterial infection. Efforts are now being directed toward evaluating the utility of biomarker profiles, containing multiple markers, for risk assessment and diagnosis in patients with suspected sepsis.

A recent paper in Critical Care by Kofoed and colleagues [1] is a good example of the promising new research in the field of sepsis diagnosis. Physicians who face the challenge of diagnosing sepsis, whether in the emergency department, on the wards or in the intensive care unit, long for the day when diagnosing this common and lethal illness will be similar to identifying patients with myocardial ischemia - that we will have at our disposal an objective set of measurements, such as an electrocardiogram, enzymes and echocardiography.

Many of us are 'jealous' at the myriad of objective measurements available to cardiologists when considering the possibility of ischemia as a source of a given set of symptoms for a patient. In the case of diagnosing sepsis, we have only a nonspecific set of signs and symptoms and the suspicion of infection to facilitate diagnosis. Many clinicians believe this is the reason why clinical cardiology trials enroll larger numbers of patients than trials in sepsis. It is not uncommon for a trial evaluating a new agent for cardiac ischemia to have more than 10,000 patents enrolled, while trials involved with determining new therapeutic agents for sepsis struggle to enroll 2,500 patients [2-5]. Over the past several years, progress has been made towards making the diagnosis of sepsis more objective. Several biomarkers have been evaluated and shown to have a moderate degree of sensitivity
Why do we need more precise diagnosis and risk assessment? In daily clinical practice the diagnosis of sepsis is imprecise and often delayed [8]. This has significant implications, as there is evidence that early events in sepsis may determine outcome [9]. In addition, the degree of organ dysfunction is correlated with increased mortality. Unfortunately, predicting the development of organ dysfunction and death remains uncertain. While biomarkers may facilitate the diagnosis of sepsis, their real value may lie in the ability to use biomarker profiles to assess risk in patients with sepsis. Although challenging, the diagnosis of sepsis may not be as significant as early risk assessment. Both are obviously important, but in clinical practice the vast majority of patients will receive empiric broad-spectrum antibiotics. Studies suggest that early intervention is important for survival in patients with severe sepsis and septic shock $[10,11]$. Accurate risk assessment, which might be used to guide the intensity of therapeutic interventions, including intensive care unit admission, may be more likely to have an impact on the management, and ultimately the outcomes, of sepsis.

What do clinicians and clinical trials expect from an 'ideal' sepsis biomarker? Several characteristics come to mind: to be highly sensitive and specific for sepsis, to allow the differentiation between infectious and noninfectious causes of inflammation, organ dysfunction and shock, to be present at the onset or even before the appearance of the clinical signs of sepsis, to have prognostic value, to indicate the severity and the course of sepsis, and to be biologically plausible. No single marker has been shown to possess such qualities, but there are encouraging signs in the literature that we are on the right path towards finding a marker or a set of markers, which will facilitate diagnosis and risk assessment in septic patients. 
The study by Kofoed and colleagues [1] illustrates this new trend in the evaluation of sepsis biomarkers. In this paper, the authors test several markers individually for their ability to discriminate bacterial versus nonbacterial causes of inflammation, and then tested a composite three-marker and sixmarker test. In their study, the area under the curve was greatest $(0.88)$ for the six-marker test. There is a very important message in this trial. Given the complexity of the inflammatory response, identifying a single marker that might precisely facilitate diagnosis and risk assessment is unrealistic. It is therefore logical that effort is now being directed toward evaluating the utility of biomarker profiles, containing multiple markers, for risk assessment and diagnosis in patients with suspected sepsis.

Several studies are now underway, utilizing biomarker profiles as a means to identify patients who are likely to progress to organ dysfunction. In the past, several markers, such as interleukin- 6 have been shown to be associated with mortality in septic patients [12]. The question remains whether sepsis biomarkers, identified from bench research, can be combined into profiles that can be used to identify patients in the early stages of sepsis who are likely to evolve organ dysfunction. In this way, an 'electrocardiogram of sepsis' may finally become a clinical reality. This kind of translational research has the potential to transform the care of these septic patients and to direct appropriate therapies to patients at risk early in the disease process. Of course, many more trials involving large populations of septic patients are needed before the 'electrocardiogram of sepsis' becomes a reality, but early results from a trial such as that of Kofoed and colleagues hold hope for all clinicians faced with the challenge of predicting risk for patients with sepsis.

\section{Competing interests}

The author declares that they have no competing interests.

\section{References}

1. Kofoed K, Andersen O, Dronborg G, Tvede M, Petersen J, EugenOlsen J, Larsen K: Use of plasma C-reactive protein, procalcitonin, neutrophils, macrophage migration inhibitory factor, soluble urokinase $\mathrm{p}$-type plasminogen activator receptor, and soluble triggering receptor expressed on myeloid cells- 1 in combination to diagnose infections: a prospective study. Crit Care 2007, 11:R38.

2. Opal S, Laterre PF, Abraham E, Francois B, Wittebole X, Lowry S, Dhainaut JF, Warren B, Dugernier T, Lopez A, et al., Controlled Mortality Trial of Platelet-Activating Factor Acetylhydrolase in Severe Sepsis Investigators: Recombinant human platelet-activating factor acetylhydrolase for treatment of severe sepsis: results of a phase III, multicenter, randomized, double-blind, placebo-controlled, clinical trial. Crit Care Med 2004, 32:332341.

3. Abraham E, Reinhart K, Opal S, Demeyer I, Doig C, Rodriguez AL, Beale R, Svoboda P, Laterre PF, Simon S, et al., OPTIMIST Trial Study Group: Efficacy and safety of tifacogin (recombinant tissue factor pathway inhibitor) in severe sepsis: a randomized controlled trial. JAMA 2003, 290:238-247.

4. Anonymous: Randomised trial of intravenous streptokinase, oral aspirin, both, or neither among 17,187 cases of suspected acute myocardial infarction: ISIS-2. ISIS-2 (Second International Study of Infarct Survival) Collaborative Group [see comment]. Lancet 1988, 2:349-360.
5. Anonymous: An international randomized trial comparing four thrombolytic strategies for acute myocardial infarction. The GUSTO investigators. N Engl J Med 1993, 329:673-682.

6. Uzzan B, Cohen R, Nicolas P, Cucherat M, Perret G: Procalcitonin as a diagnositic test for sepsis in critically ill adults and after surgery or trauma: a systematic review and meta-analysis. Crit Care Med 2006, 34:1996-2003.

7. Jensen J, Heslet L, Jensen T, Espersen K, Steffensen P, Tvede M: Procalcitonin increase in early identification of critically ill patients at high risk of mortality. Crit Care Med 2006, 34: 2596-2602.

8. Poeze M, Ramsay G, Gerlach H, Rubulotta F, Levy M: An international sepsis survey: a study of doctors' knowledge and perception about sepsis [see comment]. Crit Care 2004, 8: R409-R413.

9. Annane D, Sebille V, Charpentier C, Bollaert PE, Francois B, Korach JM, Capellier G, Cohen Y, Azoulay E, Troche G, et al:: Effect of treatment with low doses of hydrocortisone and fludrocortisone on mortality in patients with septic shock. JAMA 2002, 288:862-871.

10. Rivers E, Nguyen B, Havstad S, Ressler J, Muzzin A, Knoblich B, Peterson E, Tomlanovich M, for the Early Goal-Directed Therapy Collaborative Group: Early goal-directed therapy in the treatment of severe sepsis and septic shock. N Engl J Med 2001, 345:1368-1377.

11. Levy MM, Macias WL, Vincent J-L, Russell JA, Silva E, Trzaskoma $B$, Williams MD: Early changes in organ function predict eventual survival in severe sepsis. Crit Care Med 2005, 33:21942201.

12. Steinmetz HT, Herbertz A, Bertram M, Diehl V: Increase in interleukin-6 serum level preceding fever in granulocytopenia and correlation with death from sepsis. J Infect Dis 1995, 171:225228. 